\title{
Do male and female adolescents differ in the effect of individual and family characteristics on their use of psychotropic drugs?
}

\author{
Michèle Baumann • Elisabeth Spitz • Rosemay Predine • \\ Marie Choquet $\cdot$ Nearkasen Chau
}

Received: 24 March 2006 / Accepted: 23 May 2006

(C) Springer-Verlag 2006

\begin{abstract}
This study assesses the effects of individual and family characteristics on psychotropic drug use among male and female adolescents. The sample included 2,396 subjects attending two middle schools and two high schools. Respondents completed self-administered questionnaires covering gender, age, body mass index, smoking, alcohol use, illicit drug use, tiredness during the daytime, selfreported personality traits, family conditions, and psychotropic drug use. The data were analyzed using logistic models. The prevalence of frequent psychotropic drug use (for headache, tiredness, nervousness, anxiety, insomnia) was $43.0 \%$ overall; twice as high among girls than boys. Among the girls, frequent psychotropic drug use was associated with frequent tiredness during the daytime (adjusted odds ratio OR 2.03, 95\% CI 1.61-2.57), smoking
\end{abstract}

\author{
M. Baumann \\ Integrative Research Unit Individual and Social Development, \\ Faculty LSHASE, University of Luxembourg, \\ Luxembourg, Luxembourg \\ E. Spitz \\ Department of Psychology, University of Metz, \\ Metz, France \\ R. Predine $\cdot$ N. Chau \\ Inserm, U420, WHO Collaborative Centre, Faculté de Médecine, \\ Vandoeuvre-lès-Nancy, France \\ M. Choquet $\cdot$ N. Chau \\ Inserm, U669, PSIGIAM "Paris Sud Innovation Group \\ in Adolescent Mental Health", Maison des Adolescents, \\ Paris, France \\ N. Chau $(\bowtie)$ \\ Inserm, U669, \\ 8 rue du Breuil, \\ 54180 Heillecourt, France \\ e-mail: Nearkasen.Chau@wanadoo.fr
}

(2.02, 1.50-2.71), alcohol use (1.34, 1.04-1.74), higher body mass index $\left(>18 \mathrm{~kg} / \mathrm{m}^{2}, 1.54,1.16-2.04\right)$, poor family atmosphere $(1.33,1.03-1.72)$, and being worried (1.93, $1.53-2.43)$ or easily becoming irritable $(1.28,1.01-1.62)$. In boys the factors with significant ORs were frequent tiredness during the daytime $(2.21,1.67-2.93)$, alcohol use $(1.52,1.15-2.01)$, and being worried $(1.70,1.28-2.26)$ or easily becoming irritable $(1.42,1.06-1.89)$; univariate analysis revealed a significant relationship with smoking and family atmosphere. An association was also observed for illicit drugs in both sexes and for age $\geq 17$ years in girls. Individual and family characteristics have marked influence on psychotropic drug use among both male and female adolescents. Preventive measures should be taken to make adolescents and their parents more aware of the risks and to improve their living conditions.

Keywords Psychotropic drug use · Adolescents · Sex · Tiredness $\cdot$ Family atmosphere $\cdot$ Smoking habit .

Alcohol use $\cdot$ Personality $\cdot$ Body weight

\section{Introduction}

In Europe and the USA, general practitioners routinely prescribe psychotropic drugs [21, 31]. Several studies have reported increased prescription rates to adolescents $[6,12]$. The use of such medication represents a major public health problem. Its potential consequences include morbidity, injuries, mortality, deleterious effects on quality of life, and the cost of remedial treatments [5, 9, 12, 23, 27]. Medication may also have undesirable side-effects, lead to the development of dependency, and delay adequate management of an underlying problem. Unsupervised relief of symptoms may result in the patient neglecting to follow appropriate health- 
related advice or failing to modify dangerous habits. It should be noted that excessive drug use as a child may persist into adulthood.

It would be useful to know whether living conditions and individual characteristics influence psychotropic drug use. Several studies have shown that physical symptoms in adolescents are associated with age, physical development, gender, ethnic group, self-esteem, depression, anxiety, certain behaviors, and family and parental characteristics [33]. Rates of psychotropic drug use are well known to be higher among females [11, 13, 37]. Compared with men, women are more likely to take psychotropic drugs under medical supervision [19], to be given them following a medical consultation, to receive longer courses, and to renew the treatment [20]. Sex differences may in part be attributable to a higher incidence of depressive symptoms among females, and their greater willingness to seek medical help [3]. Psychotropic drug use may also be associated with smoking and alcohol consumption [13], both of which are more common in depressed people [25, 38]. Tiredness is common in all age groups, but particularly affects adolescents [1]. It can deteriorate individual's health and quality of life and thus can favor psychotropic drug use.

A poor body image may predispose people to depressive disorders [4] and result in adolescents becoming overweight [25]. It would therefore be interesting to examine the relationship between body mass index and long-term use of psychotropic drugs. Psychological disposition, motivation, and mental representation may also have an influence [36]. Subjects with certain personality traits are likely to be at increased risk, and women are more culturally predisposed than men to seek medical help for emotional problems. Family atmosphere also contributes to psychotropic drug use. Indeed, family plays a role in physical symptoms, depression, and tobacco, alcohol and illicit drug use [2, 7, 17, 33].

However, despite abundant literature, few studies have investigated the concurrent effects of individual and family characteristics on regular psychotropic drug use in boys and girls. A better understanding of this issue would be expected to help target preventative measures appropriately, and may have relevance to clinical practice and health promotion. The aim of the present study was to assess the relationships of age, smoking, alcohol use, illicit drug use, tiredness, body mass index, personality, and family environment, with regular psychotropic drug use in male and female adolescents from an average French town.

\section{Materials and methods}

Study sample

The study population comprised all 3,294 adolescents attending two middle schools and two high schools in the urban area of Nancy in the Meurthe-et-Moselle administrative area of north-eastern France during one school year.

\section{Design}

The investigation was approved by relevant personnel at the schools involved: the Nancy-Metz regional education authority, the Meurthe-et-Moselle school inspectorate, and the Commission Nationale de l'Informatique et des Libertés. Parents gave written consent. The study protocol was as follows:

1. A letter requesting participation was sent to parents or guardians.

2. Three weeks later, subjects completed a standardized self-administered anonymous questionnaire (during school time and under the supervision of their sports or physical training teachers). It recorded gender, birth date, height and weight (measured by the teacher), smoking habits, alcohol consumption (Frequent / Sometimes / Never or rare), illicit drug use (Frequent / Sometimes / Never or rare), frequent tiredness during the daytime, family conditions, self-reported personality traits, and psychotropic drug use. Family conditions considered were: living mainly with mother, father, or guardian; frequent absence of father and mother from home for more than 24 hours; perception of the family atmosphere (Good/Rather boring/Do not know). With regard to personality, subjects were asked whether they considered themselves: serious, organized, worried, easily irritated, or solitary (Yes/No) [7, 8]. With regard to psychotropic drugs, subjects were asked whether they frequently used medication (prescribed and non-prescribed) during the previous 12 months for headache, tiredness, nervousness or anxiety, or insomnia (Yes/No) $[5,9,10]$.

Respondents were allowed to ask the teacher if they did not understand a question, but teachers had been instructed not to say anything that might influence the response (they rarely did so). Questionnaires took 20-45 minutes to complete and were returned to the teachers in sealed envelopes ready for transfer to Unit 420 of Inserm, where the data were analyzed.

\section{Statistical analyses}

The outcome variable was frequent psychotropic drug use (all types combined). Age was categorized into four groups: 12 or under, $13-14,15-16$, and 17 or over. The other factors considered were dichotomized: body mass index (BMI) $>18 \mathrm{~kg} / \mathrm{m}^{2}$ [32], current smoker, alcohol consumption (sometimes or frequent), living with both father and mother, 
frequent absence of father and mother from home for more than 24 hours, poor family atmosphere, frequent tiredness during the daytime, and self-reported personality traits (serious, organized, worried, easily irritated, solitary). The relationships between various risk factors and psychotropic drug use were analyzed with the $\chi 2$ independence or Fisher exact tests. Adjusted odds ratios (ORs) with $95 \%$ confidence intervals (CI) were then calculated using the logistic model with stepwise forward procedure. In this model, only factors significantly related to the outcome variable $(p<0.05)$ were considered. All analyses were made for each sex separately. The comparison between the two sexes was made using the Mantel-Haenszel test and odds ratio adjusted for age ( \pm 2 years) and $95 \%$ CI. The data were analyzed using SAS software (SAS Institute, Cary, NC).

\section{Results}

Of the 3,294 pupils contacted, 2,396 (72.7\%) participated in the study $(13.0 \%$ declined, and $14.3 \%$ did not participate because they were absent or exempt from sports and physical training on the day of the survey). Table 1 shows the characteristics of the subjects. Boys accounted for $42.1 \%$. It should be noted that $20.5 \%$ were current smokers; $37.6 \%$ sometimes or often drank alcohol; and 7.2\% some-

Table 1 Characteristics of subjects (2,396 pupils): \%

\begin{tabular}{lr}
\hline Boys & 42.1 \\
Age (yr) & \\
$<12$ & 15.6 \\
$13-14$ & 16.8 \\
$15-16$ & 36.6 \\
$>17$ & 31.0 \\
Body mass index $\left(\mathrm{kg} / \mathrm{m}^{2}\right)$ & \\
$<18$ & 21.5 \\
$18-21$ & 61.9 \\
$\geq 22$ & 16.6 \\
Current smoker & 20.5 \\
Alcohol consumption (sometimes or frequent) & 37.6 \\
Illicit drug use (sometimes or frequent) & 7.2 \\
Lives with both father and mother & 94.7 \\
Father or mother often away & 12.7 \\
Poor family atmosphere & 28.7 \\
Frequent tiredness during the daytime & 44.1 \\
Self-reported personality & \\
Worried & 48.1 \\
Easily irritated & 38.3 \\
Not organized & 39.0 \\
Solitary & 27.7 \\
Not serious & 23.9 \\
Frequent psychotropic drug use during the previous & 43.0 \\
12 months & \\
\hline
\end{tabular}

${ }^{\text {a } P r e s c r i b e d ~ a n d ~ n o n-p r e s c r i b e d ~ d r u g s ~ c o m b i n e d ~}$ times or often took illicit drug(s). About one quarter of respondents reported that their family atmosphere was poor, and $44.1 \%$ stated that they were often tired during the daytime. Over the previous 12 months, 43.0\% had taken one or more psychotropic drugs (prescribed or not; $35.5 \%$ for headache, $13.7 \%$ for tiredness, $11.3 \%$ for nervousness or anxiety, and $5.3 \%$ for insomnia).

A higher proportion of girls than boys had taken psychotropic drugs. Odds ratios (OR) adjusted for age ( \pm 2 years) were: 2.51 (95\% CI 2.07-3.04, $p<0.001)$ for headache; 1.25 (0.92-1.69, NS) for tiredness; 2.03 (1.41-2.92, $p<0.001)$ for nervousness or anxiety; $2.48(1.30-4.42, p<0.01)$ for insomnia; and $2.38(2.01-2.86, p<0.001)$ for all categories combined.

Table 2 shows that smoking, alcohol consumption, illicit drug use, poor family atmosphere, and frequent tiredness during the daytime were associated with psychotropic drug use in both boys and girls. Age of 17 years or more and higher BMI had an effect only among girls. Regarding selfreported personality traits, psychotropic drug use was more prevalent in subjects of both sexes who described themselves as being worried, easily irritated or solitary, in girls who said they were not organized, and in boys who declared they were not serious.

Table 3 shows adjusted ORs for various factors. The following four were similar in both sexes: frequent tiredness during the daytime had the most marked effect with ORs of about 2, and alcohol consumption, being worried, and being easily irritated had ORs of between 1.28 and 1.93. Although smoking and family atmosphere were separately linked with psychotropic drug use, significant ORs were found in girls only. A BMI of $18 \mathrm{~kg} / \mathrm{m}^{2}$ or more was also associated with a higher risk in girls (OR 1.54) but not in boys.

\section{Discussion}

The present study reveals that $43.0 \%$ of adolescents surveyed reported frequent psychotropic drug use for headache, tiredness, nervousness, anxiety, or insomnia. It shows that frequent psychotropic drug use was associated with a number of individual and family factors. Smoking, alcohol consumption, illicit drug use, poor family atmosphere, frequent tiredness during the daytime, and certain self-reported personality traits had significant effects in both sexes. It also shows that the prevalence of psychotropic drug use among girls was double that in boys, and particularly high in girls aged $\geq 17$ and those with a BMI $\geq 18 \mathrm{~kg} / \mathrm{m}^{2}$.

The adolescents studied were all the pupils at two middle schools and two high schools in the urban area of Nancy (330,000 inhabitants). They represented 15\% of all school students in the area. The participation rate was satisfactory at $72.7 \%$. Any selection bias would be small, as the yearly 
Table 2 Relationships between individual and family characteristics and frequent psychotropic drug use

\begin{tabular}{|c|c|c|c|c|c|c|}
\hline & \multicolumn{3}{|l|}{ Boys (1,004 subjects) } & \multicolumn{3}{|l|}{ Girls (1,378 subjects) } \\
\hline & Number of subjects & $\%$ & $p$-value & Number of subjects & $\%$ & $p$-value \\
\hline Age (yr) & & & NS & & & $<0.001$ \\
\hline$<12$ & 196 & 26.0 & & 178 & 38.2 & \\
\hline $13-14$ & 178 & 30.3 & & 224 & 42.4 & \\
\hline $15-16$ & 319 & 30.4 & & 550 & 53.4 & \\
\hline$\geq 17$ & 311 & 34.4 & & 426 & 60.8 & \\
\hline Body mass index $\left(\mathrm{kg} / \mathrm{m}^{2}\right)$ & & & NS & & & $<0.001$ \\
\hline$<18$ & 216 & 31.0 & & 298 & 40.3 & \\
\hline $18-21$ & 595 & 31.3 & & 877 & 53.9 & \\
\hline$>22$ & 193 & 29.0 & & 203 & 60.6 & \\
\hline Current smoker & & & $<0.01$ & & & $<0.001$ \\
\hline Yes & 159 & 40.9 & & 329 & 70.8 & \\
\hline No & 845 & 28.9 & & 1049 & 46.0 & \\
\hline Alcohol use (sometimes or frequent) & & & $<0.001$ & & & $<0.001$ \\
\hline Yes & 420 & 38.1 & & 474 & 64.1 & \\
\hline No & 584 & 25.5 & & 904 & 45.6 & \\
\hline Illicit drug use (sometimes or frequent) & & & $<0.05$ & & & $<0.01$ \\
\hline Yes & 75 & 41.3 & & 97 & 67.0 & \\
\hline No & 929 & 29.9 & & 1281 & 50.8 & \\
\hline Lives with both father and mother & & & NS & & & NS \\
\hline Yes & 951 & 30.8 & & 1305 & 48.3 & \\
\hline No & 53 & 30.2 & & 73 & 43.8 & \\
\hline Father or mother often away & & & NS & & & NS \\
\hline Yes & 135 & 28.9 & & 166 & 59.0 & \\
\hline No & 869 & 31.1 & & 1212 & 51.0 & \\
\hline Poor family atmosphere & & & $<0.001$ & & & $<0.001$ \\
\hline Yes & 277 & 40.0 & & 406 & 61.6 & \\
\hline No & 727 & 27.6 & & 972 & 47.9 & \\
\hline Frequent tiredness during the daytime & & & $<0.001$ & & & $<0.001$ \\
\hline Yes & 706 & 28.5 & & 657 & 64.2 & \\
\hline No & 298 & 36.2 & & 721 & 40.8 & \\
\hline Self-reported personality & & & & & & \\
\hline Worried & & & $<0.001$ & & & $<0.001$ \\
\hline Yes & 370 & 40.3 & & 776 & 61.0 & \\
\hline No & 634 & 25.2 & & 602 & 40.4 & \\
\hline Easily irritated & & & $<0.001$ & & & $<0.001$ \\
\hline Yes & 338 & 38.2 & & 574 & 59.4 & \\
\hline No & 666 & 27.0 & & 804 & 46.6 & \\
\hline Not organized & & & NS & & & $<0.01$ \\
\hline Yes & 440 & 33.0 & & 490 & 56.9 & \\
\hline No & 564 & 29.0 & & 888 & 49.2 & \\
\hline Solitary & & & $<0.05$ & & & $<0.05$ \\
\hline Yes & 283 & 36.4 & & 377 & 57.3 & \\
\hline No & 721 & 28.6 & & 1001 & 50.0 & \\
\hline Not serious & & & $<0.05$ & & & NS \\
\hline Yes & 611 & 22.9 & & 269 & 56.5 & \\
\hline No & 393 & 43.0 & & 1109 & 50.9 & \\
\hline
\end{tabular}

incidence rate of school injuries was similar among participants and non-participants [32]. The quality of the completed questionnaires was very good (non-responses for various items $<4 \%$ ). As previously mentioned, all factors studied were validated and had been used elsewhere [7-10]. The items used to assess personality were chosen for their simplicity and because they have been associated with increased risk of accidents and with tobacco, alcohol and illicit drug use $[7,8]$. They were accepted by respondents and appeared to be understood. The study as a whole was well accepted by the teachers, the pupils, the schools involved, and the parents. 
Table 3 Relationships between individual and family characteristics and frequent psychotropic drug use: adjusted $\mathrm{OR}^{\mathrm{a}}$ and $95 \% \mathrm{CI}$

\begin{tabular}{|c|c|c|c|c|}
\hline \multirow[b]{2}{*}{ Body mass index $18 \mathrm{~kg} / \mathrm{m}^{2}$ or over } & \multicolumn{2}{|c|}{ Boys (1,004 subjects) } & \multicolumn{2}{|c|}{ Girls (1,378 subjects) } \\
\hline & - & & $1.54 * *$ & $1.16-2.04$ \\
\hline Current smoker & - & & $2.02 * * *$ & $1.50-2.71$ \\
\hline Alcohol consumption (sometimes or frequent) & $1.52 * *$ & $1.15-2.01$ & $1.34 *$ & $1.04-1.74$ \\
\hline Frequent tiredness during the daytime & $2.21 * * *$ & $1.67-2.93$ & $2.03 * * *$ & $1.61-2.57$ \\
\hline Poor family atmosphere & - & & $1.33 *$ & $1.03-1.72$ \\
\hline \multicolumn{5}{|l|}{ Self-reported personality } \\
\hline Worried & $1.70 * * *$ & $1.28-2.26$ & $1.93 * * *$ & $1.53-2.43$ \\
\hline Easily irritated & $1.42 *$ & $1.06-1.89$ & $1.28^{*}$ & $1.01-1.62$ \\
\hline
\end{tabular}

$* P<0.05, * * P<0.01, * * * P<0.001$

${ }^{a}$ Using logistic model by including the factors significantly related $(P<0.05)$ to the outcome variable (Table 2$)$

For simplicity, only odds ratios for which $P<0.05$ are presented

The present study reports that frequent psychotropic drug use was common in the adolescents surveyed (43.0\%). Rhee et al. [35] also reported that headache and fatigue were common among adolescents. Furu et al. [15] found that $41 \%$ of boys and $64 \%$ of girls used drugs during the four weeks preceding the survey. With regard to living conditions, in our study $44.1 \%$ of respondents were often tired during the daytime, and tiredness was the main risk factor for frequent psychotropic drug use (adjusted OR approximately 2 for both boys and girls). A high prevalence of fatigue was also observed in other studies [35]. Sleep problems and chronic fatigue favor depression $[4,34]$. In addition, they may lead to difficulty working, which is also associated with depression [4]. These findings underline the importance of investigating the causes of frequent tiredness in adolescents.

The relationships between tobacco, alcohol, and illicit drug use and psychotropic drug intake were as expected. Indeed, all three may alter health status and living conditions. Smoking and alcohol problems are more common in depressed people [25, 30, 38]. Smoking affects physical functions and is associated with loss of cognitive flexibility, degenerative forms of cognitive impairment $[18,28]$, and sleep disorders [16]. Thus, smoking may alter the capacity of pupils to work. In the present study, the difference in the frequency of psychotropic drug use between users and nonusers of tobacco, alcohol, or illicit drugs was greater among girls than among boys.

An important finding here was that a poor family atmosphere was associated with frequent use of psychotropic medication. Depression and substance use are markedly associated with difficulties in the family, and particularly with a negative perception of the home atmosphere, and a lack of strength of family ties, sense of family happiness, structure of authority in the family, and family support $[2,7,11,17]$. These observations highlight the importance of family relations during adolescence. In fact, this issue concerns all age groups; indeed, an association between familial instability and illicit or unprescribed drug use was observed in a nationwide sample of the general population [24].
The present work highlights the fact that certain selfreported personality traits are associated with frequent psychotropic drug use. Adolescents who described themselves as worried, serious, easily irritated, not organized, or solitary were at higher risk. The personality traits most associated with risk were being worried and, to a lesser degree, being easily irritated. It is possible that adolescents who are afraid of the future or who live in poor conditions would have negative personality traits and altered wellbeing, and consequently use more psychotropic drugs.

This investigation confirms a two-fold higher prevalence of regular psychotropic drug use in girls compared with boys. Furu et al. observed the same pattern among 1516 year-olds in Norway [31]. A sex-ratio of about two was reported among adults ( $\geq 18$ years) in the Lorraine area of north-eastern France (a region of 2.3 million inhabitants that includes Nancy) [11] and among adults in six European countries (for the use of an antidepressant, anxiolytic, antipsychotic or mood stabilizing agents during the previous 12 months) [13]. The evidence indicates that preventative measures should target young people in order to reduce drug use in adulthood. Here, the difference between girls and boys was greater in the subjects aged 17 years or more $(60.8 \%$ vs. $34.4 \%)$ than in those aged 12 years or less $(38.2 \%$ vs. $26.0 \%$ ). Furthermore, a higher risk was observed in girls with a BMI of $18 \mathrm{~kg} / \mathrm{m}^{2}$ or more. This was consistent with the finding by Bennett et al. that depressed girls had more body image dissatisfaction [4]. Psychosomatic disorders are commonly reported among subjects with advanced pubertal status [34]. Therefore, prevention should focus particularly on girls.

Although this study was conducted in a large enough sample, the results should be interpreted with caution due to the presence of a possible selection bias and the use of an auto-questionnaire. However, self-administered questionnaire is reliable and valid [22]. A study analyzing nonresponse bias in a mailed health survey showed that respondents and non-respondents were of similar sex and age distributions, and the proportion of people having a 
health care expenditure was very slightly higher in respondents $(75 \%$ vs. $69 \%)$ [14].

Our findings may have relevance to clinical practice and health promotion. They reveal that living conditions and individual characteristics play marked roles in regular psychotropic drug use. The adolescents and their parents, the staff at the schools and the practitioners concerned, should be informed about the problem. The adolescents should be helped to improve their living conditions, paying particular attention to tobacco, alcohol, and illicit drug use, tiredness, satisfaction with body image, and family atmosphere. Pupils with certain personality traits warrant more attention and more help to address their problems and to limit psychotropic drug use. When young people are prescribed psychotropic drugs, they should be informed about how to optimize the benefit/risk ratio. Physicians may find the results of interest, particularly if they are womenas female doctors tend be more receptive to what their patients say and to prescribe psychotropic drugs more often than their male counterparts, whatever the indication [26]. The epidemiological data in the literature suggest that the risk of inappropriate use of psychotropic drugs is high and that adolescents with mental disorders (and their parents) must be guaranteed appropriate care [6].

Acknowledgements The authors would like to thank A. d'Houtaud, E. Aptel, B. Mergel, E. Berton, P. Pierre, R. Franiatte, Y. Charron, F. Willer, J.P. Thirion, M.L. Thirion, N. Jurin, C. Mathis, F. Claudin, E. Predine, L. Benamghar, J.P. Michaely, D. Saouag, M. Weiss, M. Depesme, B. Phélut, J. Ciccone, N. Lorentz, and teachers of the schools for their help.

\section{References}

1. Armengaud D (2005) Chronic fatigue and sleep disorders in adolescents. Rev Prat 55:1095-1098

2. Aseltine RH, Gore S, Colten ME (1998) The co-occurrence of depression and substance abuse in late adolescence. Dev Psychopathol 10:549-570

3. Baumann M, Pommier J, Deschamps JP (1997) Sociologie de la santé: comportements de «genre» chez les adolescents et psychotropes. Connexions 69:155-166

4. Bennett DS, Ambrosini PJ, Kudes D (2005) Gender differences in adolescent depression: Do symptoms differ for boys and girls? J Affect Disord 89:35-44

5. Bhattacherjee A, Chau N, Otero Sierra C, Legras B, Benamghar L, Michaely JP, Ghosh AK, Guillemin F, Ravaud JF, Mur JM, Lorhandicap group (2003) Relationships of job and some individual characteristics to occupational injuries in employed people: A community-based study. J Occup Health 45:382-391

6. Bonati M, Clavenna A (2005) The epidemiology of psychotropic drug use in children and adolescents. Int Rev Psychiatry 17:181-188

7. Challier B, Chau N, Predine R, Choquet M, Legras B (2000) Associations of family environment and individual factors with tobacco, alcohol and illicit drug uses in adolescents. Eur J Epidemiol 16:33-42

8. Chau N, D'Houtaud A, Gruber M, Monhoven N, Gavillot C, Pétry D, Bourgkard E, Guillaume S, André JM (1995) Personality self-representations of patients with hand injury, and its relationship with work injury. Eur J Epidemiol 11:373-382

9. Chau N, Predine R, Benamghar L, Michaely JP, Choquet M, Ciccone J, Lorentz N, Aptel E, Mergel B, D’Houtaud A (1999) Déterminants socio-démographiques, individuels et familiaux d'accidents scolaires multiples. Congrès Médecine et Santé de l'Adolescent «Accidents, répétition d'accidents à l'adolescence», Poitiers, 4 December

10. Chau N, Ravaud JF, Bourgkard E, Sanchez J, Choquet M, Meyer JP, Otero Sierra C, Michaely JP, Legras B, Guillemin F, Bhattacherjee A, Guillaume S, Dazord A, Méjean L, TubianaRufi N, Schléret Y, Mur JM (2004) Relationships of demanding work conditions with fatigue and psychosomatic disorders: A community-based study. 17th international symposium on epidemiology in occupational health, Melbourne, Australia, 13-16 October 2004. Occup Environ Med 61(11):e46

11. Cohidon C, Alla F, Chau N, Michaely JP, groupe Lorhandicap (2005) Tobacco, alcohol and psychotropic drugs in Lorraine, epidemiological survey of the general population. Sante Publique 17:325-338

12. David JC, Marcelli D (2005) Should psychotropic drugs be prescribed to adolescents? Rev Prat 55:1081-1084, 1087-1088

13. ESEMeD/MHEDEA 2000 investigators (2004) Psychotropic drug utilization in Europe: results from the European Study of the Epidemiology of Mental Disorders (ESEMeD) project. Acta Psychiatr Scand 109 (Suppl. 420):55-64

14. Etter JF, Pernejer TV (1997) Analysis of non-response bias in a mailed health survey. J Clin Epidemiol 50:1123-1128

15. Furu K, Skurtveit S, Rosvold EO (2005) Self-reported medical drug use among 15-16 year-old adolescents in Norway. Tidsskr Nor Laegeforen 125:2759-2761

16. Hoffstein V (2002) Relationship between smoking and sleep apnea in clinic population. Sleep 25:519-524

17. Jedrzejczak M (2005) Family and environmental factors of drug addiction among young recruits. Mil Med 170:688-690

18. Kalmijn S, van Boxtel MPJ, Verschuren MWM, Jolles J, Launer LJ (2002) Cigarette smoking and alcohol consumption in relation to cognitive performance in middle age. Am J Epidemiol 156:936-944

19. Laget J (2000) Prescription de psychotropes chez l'adolescent. Rev Med Suisse Romande 120:117-122

20. Ledoux S, Choquet M, Manfredi R (1994) Self-reported use of drugs for sleep or distress among French adolescents. J Adolesc Health 15:495-502

21. Legrain M, Lecomte T (1998) La consommation de psychotropes en France et dans quelques pays européens. Ann Pharmacologie Française 56:67-75

22. Lewis RJ, Friedlander BR, Bhojani FA, Schorr WP, Salatich PG, Lawhorn EG (2002) Reliability and validity of an occupational health history questionnaire. J Occup Environ Med 44:39-47

23. Licinio J, Wong ML (2005) Depression, antidepressants and suicidality: a critical appraisal. Nat Rev Drug Discov 4165-171

24. Madianos MG, Madianou D, Stefanis C (1995) Familial correlates of drug and alcohol use in a nationwide general population survey. Psychopathology 28:85-94

25. McElroy SL, Kotwal R, Malhotra S, Nelson EB, Keck PE, Nemeroff CB (2004) Are mood disorders and obesity related? A review for the mental health professional. J Clin Psychiatry 65:634-651

26. Morabia A, Fabre J, Dunand J (1992) The influence of patient and physician gender on prescription of psychotropic drugs. J Clin Epidemiol 45:111

27. Nardi DA, Barrett S (2005) Potential effects of antidepressant agents on the growth and development of children and adolescents. J Psychosoc Nurs Ment Health Serv 43:22-35 
28. Nelson HD, Nevitt MC, Scott JC, Stone KL, Cummings SR (1994) Smoking, alcohol, and neuromuscular and physical function of older women. Study of Osteoporotic Fractures Research Group. JAMA 273:1825-1831

29. Nurco DN, Blatchley RJ, Hanlon TE, O’Grady KE (1999) Early deviance and related risk factors in the children of narcotic addicts. Am J Drug Alcohol Abuse 25:25-45

30. Paperwalla KN, Levin TT, Weiner J, Saravay SM (2004) Smoking and depression. Med Clin North Am 88:1483-1494

31. Pelissolo A, Boyer P, Lepine JP, Bisserbe JC (1996) Epidémiologie de la consommation des anxiolytiques et des hypnotiques en France et dans le monde. Encéphale 22: 187-196

32. Prédine R, Chau N, Lorentz N, Prédine E, Legras B, Benamghar L, Pierson A, Guillaume S, Aptel E, Mergel B (2002) Les accidents scolaires dans des établissements d'enseignement général: incidence, causes, et conséquences. Rev Epidemiol Sante Publ 50:265-276

33. Rhee H (2003) Physical symptoms in children and adolescents. Annu Rev Nurs Res 21:95-121

34. Rhee H (2005) Relationships between physical symptoms and pubertal development. J Pediatr Health Care 19:95-103

35. Rhee H, Miles MS, Halpern CT, Holditch-Davis D (2005) Prevalence of recurrent physical symptoms in U.S. adolescents. Pediatr Nurs 31:314-319

36. Ryan N, Bhatara V, Perel J (1999) Mood stabilizers in children and adolescents. J Am Acad Child Adolesc Psychiatry 38:529-536

37. Simoni-Wastila L (1998) Gender and psychotropic drug use. Med Care 36:88-94

38. Sullivan LE, Fiellin DA, O'Connor PG (2005) The prevalence and impact of alcohol problems in major depression: a systematic review. Am J Med 118:330-341 